\title{
Erratum to: Electron Magnetic Resonance in Magnetic Nanoparticles: Dependence on the Particle Size and Applicability of the Modified Giant Spin Model
}

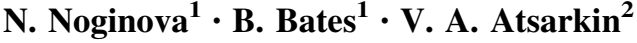

\section{Erratum to: Appl Magn Reson DOI 10.1007/s00723-016-0804-6}

Unfortunately, the references were published incorrectly in the original article. The correct references are given below:

3. Yu.L. Raikher, V.I. Stepanov, Sov. Phys. JETP 75, 764 (1992)

4. Yu.L. Raikher, V.I. Stepanov, Phys. Rev. B 50, 6250 (1994)

The online version of the original article can be found under doi:10.1007/s00723-016-0804-6.

\section{N. Noginova}

nnoginova@nsu.edu

$1 \quad$ Norfolk State University, Norfolk, VA, USA

2 Kotel'nikov Institute of Radio Engineering and Electronics, Russian Academy of Science, Moscow, Russia 